\title{
A Preliminary Study on the Function of Silent Pauses in L1 and L2 Speakers of English and German ${ }^{1}$
}

\begin{abstract}
The aim of the present paper is to provide comparative analysis regarding the functions of pauses through exploration of the similarities and differences in semantically identical utterances in micro-textual units in colloquial style produced by L1 and L2 speakers of English and German. The research study illustrates inappropriate segmentation of the discourse, inapt distribution and frequency of pause types in L2 subjects' utterances, which may be due to the fact that L2 speakers apply cognitive activities different from L1 speakers. L1 subjects' productions, on the other hand, indicate that they tend to plan and program their utterances in longer blocks.
\end{abstract}

Key words

Suprasegmentals; silent pause; functions of pauses; classifications of pauses; emphasis; discourse analysis

\section{Introduction - theoretical basis}

Being a motor activity, speech production cannot be continuous - hence interruptions and pauses are indispensable. Physiologically predictable pauses coincide with the inspiration segment of respiration since phonation is related to respiratory activity. Pauses resulting from the physiological need to resume breathing are under the speakers' control and take place more frequently in turn exchanges and at the end of intonational groups (Zellner 1994, Viola and Madureira 2008). Pauses also play an important role in the rhythmic patterning of speech in that word groups are uttered at a particular rate and are divided by pauses. Pauses are also grammar facts marking the boundaries of intonation groups and coinciding 
with syntactic boundaries (Viola and Madureira 2008, Sabol and Zimmermann 1984). Thus, pauses not only break up the speech but also organize a speaker's monologue or interaction between two or more speakers (Viola and Madureira 2008, Sabol and Zimmermann 1984). Research studies (cf. Stock 1996) indicate that comprehension of an L2 to a large extent depends on segmenting the continuous speech signal into smaller portions. Spoken language is thus segmented by means of pauses and written language by means of punctuation. If the segmentation is inappropriate for a listener (e.g. due to the speaker's state of mind), the listener gets distracted and comprehension is hindered. Segmentation is spreading out the stream of words by means of pauses into meaningful units ("Wortgruppen"), which can be regarded as an essential tool in structuring texts.

Research studies by Sabol (2006) show that a speaker can exploit a number of acoustic features which indicate the hierarchy of expressions and enhance the hearer's comprehension. Thus, an emphasized word, the most important section of an utterance, is delimited and identified by a number of prosodic features, e.g. increased volume, slower speech rate and change in the melody. In addition, there is a close relationship between a pause and an emphasis in that a speaker draws a perceiver's attention to an emphasis by means of a longer pause and at the same time gets ready for a greater articulatory effort needed for the production of an emphasized expression. What is more, his experimental measurements show that the pause preceding an emphasized word is communicatively more important than the one following it. Such a pause prepares a perceiver for the most important portion of an utterance whereas the pause following the emphasized word completes its delimitation and thus the perceiver may not be fully aware of it. What is more, experimental studies illustrate that the pre-emphatic pause is longer than the post-emphatic pause (with the exception of free verse). Thus, Sabol (2006) concludes, the interaction of the two prosodic features (pause and emphasis) is evident and it serves communication. Therefore, it should be accounted for in the realization of spoken utterances. Similarly, Strangert (2007) regards pausing as a function of focusing words and notes that pauses as a rule occur after grammatical words and before semantically heavy words thereby enhancing their status and giving them extra emphasis.

Viola and Madureira (2008) classify pauses from several aspects - from the structural, functional and distributional points of view. From the structural aspect, pauses can be divided into silent, filled or pause phenomena expressed by acoustic-phonetic features such as lengthening, changes in voice quality and F0 variation (i.e., variation in fundamental frequency). The filled pauses are those that include a non-linguistic element, such as, lengthening of part of a word, most frequently a vowel (type [a:], [o:]) or sounds such as [m:]. From the functional point of view, pauses can be classified into respiratory (taking breath), discursive (planning the discourse and structuring parts of the discourse) and expressive (expressing attitudes and emotions and subcategories of expressive pauses include, among others, dramatic and emphatic uses) (Viola and Madureira, 2008). From the distributional point of view, pauses can occur within or between sentences 
and other morpho-syntactic constituents. Experiments show that pauses tend to correlate fairly well with phrase boundary ${ }^{2}$ although researchers conclude that temporal segmentation is not really equivalent to the syntactic structure of utterances (Zellner 1994). From the functional point of view, Sabol and Zimmermann (1979: 228) differentiate the following types of pauses: physiological, communicative, expressive, hesitation pauses, etc.

From the temporal point of view, Sabol and Zimmermann (1984: 227-228) differentiate seven types of pauses:

1. Zero pause or extremely short pause $(\leq 50 \mathrm{~ms})$

2. Very short pause $(50 \mathrm{~ms}-\leq 100 \mathrm{~ms})$

3. Short pause ( $100 \mathrm{~ms}-\leq 300 \mathrm{~ms})$

4. Normal/optimal (300 $\mathrm{ms}-\leq 1350 \mathrm{~ms})$

5. Long pause (1 $350 \mathrm{~ms}-\leq 2200 \mathrm{~ms})$

6. Very long pause $(2200 \mathrm{~ms}-\leq 2800 \mathrm{~ms})$

7. Extremely long pause ( $\geq 2800 \mathrm{~ms})$.

Campione and Véronis (2002) provide a tri-modal classification, suggesting that the distributions result from a combination of three categories of pause, namely brief, medium and long.

Zellner (1994) presents two classifications of pause - the former being physical and linguistic and the latter being psychological and psycholinguistic. Within the former classification, intra-segmental pauses (e.g. VOT, i.e., voice onset time, for plosives) and inter-lexical pauses are differentiated (Zellner 1994: 42). The latter classification deals with pauses in terms of their origin (individual physiological constraints or temporal constraints) and function (pauses as reflection of cognitive activity and situational constraints).

\subsection{Psycholinguistic Classification}

Zellner (1994) stresses that psycholinguistic research studies provide ample evidence showing that perceived pauses are not really equal to physical pauses. This observation results from a law of perception (manifested in the visual, auditory, or in the tactile domain) in accordance with which the perceptual threshold is situated above the actual physical stimulus. Moreover, amplitude curves measured in detailed perceptual tests differ systematically from curves measured directly on the physical stimulus.

Therefore, Zellner (1994) illustrates, some pauses are more easily perceived than others and, as a rule, their perceptual dominance is enhanced by their particular functions within the message, such as grammatical functions, semantic focus, hesitation, and so on. 


\subsection{Classification in terms of origin}

This classification (Zellner 1994: 41-62) takes into account three types of constraints: individual, temporal and situational. Since speech motor activity is essentially an individual activity, the incidence of pauses is largely dependent on the specific speaker (weak respiration, low muscular tone, and slow articulatory rate generally result in a greater number of pauses whereas a rapid articulatory rate and good respiratory capacity cause their number to diminish. In addition, pauses, as has already been mentioned, tend to occur between rhythmic groups. ${ }^{3}$ A consideration of the situational context is also crucial because that can have an impact on the speaker's expressive capacities (e.g. speaking under pressure, performing an extremely complex communicative task, being under emotional stress, etc.).

\subsection{The function of perceived inter-lexical pauses (in excess of $200 \mathrm{~ms}$ )}

Apart from the largely physiological origins of the pauses occurring on a fairly regular basis (respiratory pauses), it is also possible to recognize a number of cognitive origins for pauses (discursive pauses that result from planning and organizing the components of the utterance).

\subsection{Pauses as a reflection of a cognitive activity}

A pause is the external manifestation of some of the cognitive processes involved in speech production in that pauses provide extra time for planning and programming the final production (Zellner 1994). Therefore, when producing a comparatively complex utterance a speaker tends to think a long time before providing a response. On the other hand, it can also be observed that sometimes, a speaker begins to respond immediately, and then may stop and take some time before resuming speech or may rephrase the utterance. Zellner (1994: 46-47) concludes that "in this case, the hypothesis proposes that "speech has raced ahead of cognitive activity" and that the pause reflects the time needed for the cognitive planning process to catch up".

Furthermore, Zellner (1994) illustrates that the Goldman-Eisler hypothesis further predicts a universally observed distinction between spontaneous and read speech. Spontaneous speech is much more frequently interrupted by pauses of cognitive origin than read speech. What is more, this feature, together with other reflections of cognitive activity (such as false starts, filled pauses, stuttering, etc.), is not regarded as a "nuisance variable" and is a manifestation of normal nonfluency. 


\subsection{Pauses acting as "beacons" for utterances}

A number of psycholinguistic investigations have shed light on how pauses are distributed and revealed that the more complex the communicative task, the greater the number of pauses. Thus, pauses may serve as "beacons" (Zellner 1994), subdividing speech into smaller portions and organizing the entire utterance for both speaker and listener. Therefore, pauses are vital for speech comprehension.

In the present study, Viola and Madureira's (2008) classification of pause functions has been applied with the additions of multifunctional pause and nonfunctional pause. The latter, though they may appear as hesitation pauses are pauses resulting from the speaker's obvious uncertainty related to insufficient language competence, e.g. regarding the pronunciation, complex grammatical structure, vocabulary, etc.

\section{Experiment}

\subsection{Hypothesis}

Some earlier investigations of L1 speakers' perception of productions by Slovak learners of a second language have indicated that Slovak learners tend to use inappropriate phrasing and pausing, which eventually affects communication. Therefore, it is hypothesized that acoustic measurements and subsequent analysis of pauses according to the functional point of view may support this observation and show differences in pausing between L1 speakers of English and German on the one hand and Slovak learners of English and German (teacher trainees) on the other hand.

\subsection{Method and material}

The material included simple and semantically equivalent dialogues in English and German consisting of an identical number of sentences (seven). The topic of the dialogues was related to hotel services. The three groups of subjects (L2 speakers of English and German, L1 speakers of English and L1 speakers of German) were each randomly divided into eight pairs. Each pair read the dialogue twice, swapping their parts. The German dialogues were read aloud by ten L2 speakers (enrolled in their first year in two programs - English language and literature and German language and literature) and six L1 speakers of German. The English dialogues were read aloud by the same ten L2 speakers and six L1 speakers of English. Since the dialogues only contained simple sentence structures and everyday vocabulary, the L2 subjects were not asked to rehearse the dialogues, they were given a few minutes to skim read them. Subsequently, all the subjects were asked to read a part of the dialogue as naturally as possible. Thus, the first readings were immediately recorded. The dialogues were recorded in a sound- 
treated recording studio using high-quality professional equipment and under the supervision of an expert in digital recording. In addition, only one pair of subjects at a time was present in the studio so that the following pair might not be affected by their performance. The whole recording was further processed (dynamics, frequency, mastering) and burnt on a CD. For the acoustic measurements Steinberg Software was used, specifically the program Wave Lab 6.

The following screen print-out illustrates the identification of silent pauses (and the measurement procedure):

Figure 1. Identification of silent pauses (Wave Lab 6)

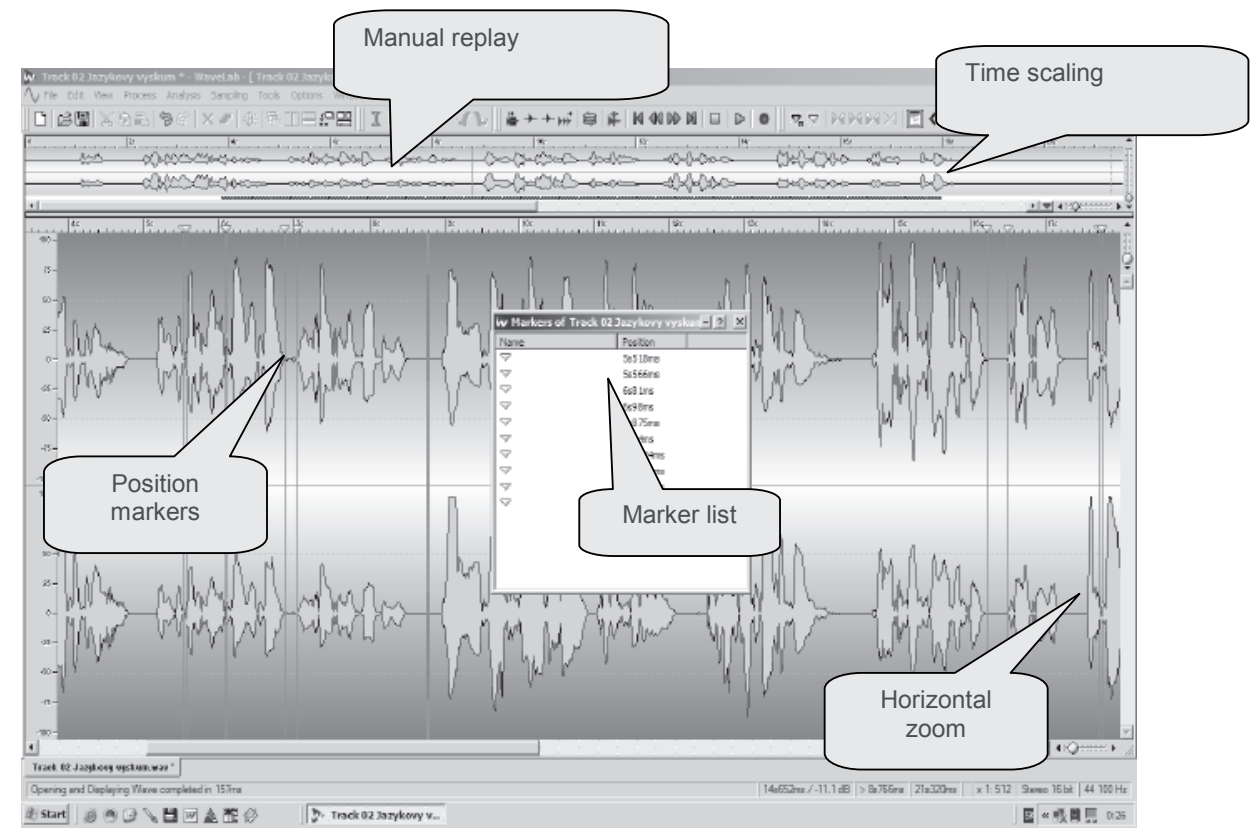

\subsection{Results}

The intra-sentence pauses were used for analysis due to the fact that read dialogues comprising short exchanges were investigated. Research studies in pausology illustrate that the pause preceding the emphasized word prepares the recipient to comprehend the most important segment of the utterance whereas the pause following the emphasized word has a delimitative function (Sabol 2006: 171-172). Pauses preceding the emphasized word were not found in the presented material, which may result from the fact that the exchanges in the investigated dialogues were short and syntactically simple.

Measurements and subsequent analysis of differences in the duration of pauses were carried out in a previous research study; the focus of the present study is an analysis of pauses from the functional point of view in the three groups of 
subjects. The analysis also draws on Firbas' theory of FSP (Svoboda 2005) and its notion of communicative dynamism which operates on a sliding scale and the degrees of communicative dynamism are relative degrees of communicative importance by which the elements contribute to the development of communication. The degrees of communicative dynamism (information load) are determined by the interaction of four factors - linearity (word order), semantics, context and intonation which decide whether the element functions as thematic (the point of departure), transitional or rhematic (the core of the message). Rhematic elements are typically marked by prosodic features (emphasis) and in the following tables they are printed in bold letters.

The first part of the analysis deals with the L2 subjects' performances.

\section{Sentence 1: Good morning. / Guten Tag!}

Naturally, the utterances were produced without any pauses by all L2 and L1 subjects in both languages.

Sentence 2: We would like a double-room, here in the vicinity, for one night.

\begin{tabular}{|l|l|l|l|l|l|l|l|l|l|l|l|l|}
\hline L2 1 & We & would & like & a & double-room & here & in & the & vicinity $\mathbf{5 6}$ & for & one & night \\
\hline L2 2 & We & would & like & a & double-room $\mathbf{1 5 7}$ & here & in & the & vicinity 202 & for & one & night \\
\hline L2 3 & We & would & like & a & double-room $\mathbf{3 1 5}$ & here & in & the & vicinity $\mathbf{1 5 4}$ & for & one & night \\
\hline L2 4 & We & would & like & a & double-room & here & in & the & vicinity 39 & for & one & night \\
\hline L2 5 & We & would & like & a & double-room $\mathbf{6 8}$ & here & in & the & vicinity 219 & for & one & night \\
\hline L2 6 & We & would & like & a & double-room $\mathbf{1 2 0}$ & here & in & the & vicinity 209 & for & one & night \\
\hline L2 7 & We & would & like & a & double-room $\mathbf{2 7 6}$ & here & in & the & vicinity 112 & for & one & night \\
\hline L2 8 & We & would & like & a & double-room & here & in & the & vicinity 35 & for & one & night \\
\hline L2 9 & We & would & like & a & double-room & here & in & the & vicinity 49 & for & one & night \\
\hline L2 10 & We & would & like & a & double-room $\mathbf{2 9 4}$ & here & in & the & vicinity 162 & for & one & night \\
\hline
\end{tabular}

The potential placement of pauses was graphologically indicated by commas and prompted the placement of pauses in L2 subjects. The first pause followed the first and weightiest block of information manifested also by emphasis (what - doubleroom) and the subsequent one following a less important block of information (where - vicinity) and consequently optional emphasis. Six L2 speakers (L2 2, L2 3, L2 5, L2 6, L2 7 and L2 10) produced discursive pauses (following both the first and the second block of information) after the emphases. Such segmentation of the utterance into single information blocks can be regarded as appropriate as it helps to organize the discourse for both the producer and the perceiver. Four L2 subjects (L2 1, L2 4, L2 8 and L2 9) produced respiratory pauses (following the second block of information after the word vicinity) that were identified by the friction noise present at higher frequencies in the broadband spectrogram. 
All pauses can be regarded as appropriate and non-disturbing and their durations were of extremely short and very short duration $(56 \mathrm{~ms}, 39 \mathrm{~ms}, 35 \mathrm{~ms}$ and $49 \mathrm{~ms})$. All the pauses produced by L2 subjects in this sentence were in post-position, i.e. following the emphasis.

\begin{tabular}{|l|l|l|l|l|l|l|l|l|l|l|l|l|}
\hline L1 1, L1 2, L1 4, L1 5 & We & would & like & a & double-room & here & in & the & vicinity & for & one & night \\
\hline L1 3, L1 6 & We & would & like & a & double-room & here & in & the & vicinity & for & one & night \\
\hline
\end{tabular}

No pause excessive of $50 \mathrm{~ms}$ (extremely short pause) was observed in L1 speakers' utterances. This may be a reflection of their cognitive activity - planning and programming the utterance in larger portions than L2 speakers (who may also need more planning time for correct pronunciation and grammatical patterning). In all L1 subjects the weightiest block of information was only manifested by one emphasis (what - double-room) and in two subjects (L1 3 and L1 6) apart from the major piece of information, the subsequent block representing a minor block of information (where - vicinity) was also marked by an optional emphasis.

Sentence 2: Wir möchten ein Doppelzimmer hier in der Nähe für eine Nacht.

\begin{tabular}{|l|l|l|l|l|l|l|l|l|l|l|l|}
\hline L2 1 & Wir & möchten & ein & Doppelzimmer 284 & hier & in & der & Nähe 126 & für & eine & Nacht \\
\hline L2 2 & Wir & möchten & ein & Doppelzimmer 156 & hier & in & der & Nähe & für & eine & Nacht \\
\hline L2 3 & Wir & möchten & ein & Doppelzimmer & hier & in & der & Nähe 411 & für & eine & Nacht \\
\hline L2 4 & Wir & möchten & ein & Doppelzimmer 189 & hier & in & der & Nähe & für & eine & Nacht \\
\hline L2 5 & Wir & möchten & ein & Doppelzimmer & hier 59 & in & der & Nähe & für & eine & Nacht \\
\hline L2 6 & Wir & möchten & ein & Doppelzimmer 231 & hier & in & der & Nähe 183 & für & eine & Nacht \\
\hline L2 7 & Wir & möchten & ein & Doppelzimmer 263 & hier & in & der & Nähe 117 & für & eine & Nacht \\
\hline L2 8 & Wir & möchten & ein & Doppelzimmer 165 & hier & in & der & Nähe & für & eine & Nacht \\
\hline L2 9 & Wir & möchten & ein & Doppelzimmer 258 & hier & in & der & Nähe 168 & für & eine & Nacht \\
\hline L2 10 & Wir & möchten & ein & Doppelzimmer & hier & in & der & Nähe 379 & für & eine & Nacht \\
\hline
\end{tabular}

Four L2 speakers (L2 1, L2 6, L2 7 and L2 9) produced discursive pauses following both the first and second block of information after the emphases (was - Doppelzimmer, wo - Nähe). Such segmentation (analogical with the one manifested in the English version) of the utterance into partial information blocks can be considered as suitable owing to the above given reason. Three L2 speakers (L2 2, L2 4 and L2 8) produced discursive pauses following the weightiest block of information (was - Doppelzimmer), which can be regarded as appropriate. Two L2 speakers (L2 3 and L2 10) paused following the second block of information (wo-Nähe). These are the only pauses in the whole utterances and, what is more, they are considerably longer (411 $\mathrm{ms}$ and $379 \mathrm{~ms}$ ) if compared with the pauses produced by other L2 speakers and were identified as respiratory pauses (due to the friction noise present at higher frequencies in the broadband spectrogram). Even though these pauses may be regarded as non-disturbing, the fact that the 
subjects did not emphasize the word Doppelzimmer and did not pause after this word either might result in the perceiver requesting a more specific piece of information by asking (e.g. Was für ein Zimmer?). Therefore, the position of the pauses after the weightiest block of information (was - Doppelzimmer) appears to be more appropriate. Another L2 speaker (L2 5) segmented the whole utterance in a different manner, pausing after the emphasized word hier. The pause in question slightly changed the meaning of the utterance drawing the hearer's attention to the piece of information related to the more general specification (cf. Svoboda, 2005). Based on the friction noise present at higher frequencies in the broadband spectrogram it was identified as a respiratory pause. In the given context, however, it may also be ascribed a communicative character, thus, it was categorized as a respiratory-discursive pause. Nevertheless, we may regard the pause as non-disturbing also due to its extremely short duration (59 ms).

\begin{tabular}{|l|l|l|l|l|l|l|l|l|l|l|l|}
\hline L1 1, L1 3, L1 4, L1 5, L1 6 & Wir & möchten & ein & Doppelzimmer & hier & in & der & Nähe & für & eine & Nacht \\
\hline L1 2 & Wir & möchten & ein & Doppelzimmer & hier 95 & in & der & Nähe & für & eine & Nacht \\
\hline
\end{tabular}

One L1 speaker (L12) produced a respiratory pause (qualified as such according to the above-given criteria) following the word hier, which was emphasized, thus defining the first block of information. It appears to be more appropriate to place the emphasis on the word Doppelzimmer since this expression carries more information load. In spite of this fact, the shift of pause, emphasis and, consequently, in the meaning may be regarded as non-disturbing as the speaker apparently focused on a more specific bit of information (related to the location). In addition, the pause exhibits very short duration $(95 \mathrm{~ms})$. The fact that the remaining L1 subjects produced this utterance without any pause may be ascribed to their cognitive activity and the resulting rate of articulation.

Sentence 3: It would be possible in the Crown Hotel, in the center, not far from here.

\begin{tabular}{|l|l|l|l|l|l|l|l|l|l|l|l|l|l|l|l|}
\hline L2 1 & It & would & be 35 & possible & In & the & Crown & Hotel 139 & in & the & center 372 & not & far & from & here \\
\hline L2 2 & It & would & be & possible & In & the & Crown & Hotel 259 & in & the & center 260 & not & far & from & here \\
\hline L2 3 & It & would & be & possible & In & the & Crown & Hotel 84 & in & the & center 351 & not & far & from & here \\
\hline L2 4 & It & would & be 32 & possible & In & the & Crown & Hotel 179 & in & the & center & not & far & from & here \\
\hline L2 5 & It & would & be & possible & In & the & Crown & Hotel 67 & in & the & center 484 & not & far & from & here \\
\hline L2 6 & It & would & be & possible & In & the & Crown & Hotel 302 & in & the & center 67 & not & far & from & here \\
\hline L2 7 & It & would & be 41 & possible & In & the & Crown & Hotel 139 & in & the & center 295 & not & far & from & here \\
\hline L2 8 & It & would & be & possible & In & the & Crown & Hotel 84 & in & the & center 432 & not & far & from & here \\
\hline L2 9 & It & would & be & possible & In & the & Crown & Hotel 77 & in & the & center 412 & not & far & from & here \\
\hline L2 10 & It & would & be & possible & In & the & Crown & Hotel 238 & in & the & center 302 & not & far & from & here \\
\hline
\end{tabular}

All ten L2 subjects produced a discursive pause after the first and weightiest block of information (which hotel - Crown Hotel). Likewise, all L2 subjects except for one (L2 4) made a discursive pause also after the second block of information, 
after the emphasized word (where - center). Both manners of segmentation of the utterance may be regarded as appropriate. Two L2 subjects (L2 1 and L2 7), in addition to the discursive pauses, produced hesitation pauses after another emphasized word (be). Similarly, the L2 4 subject, in addition to the discursive pause, produced a hesitation pause after the emphasized word (be). The three hesitation pauses were negligible and non-disturbing owing to their extremely short duration ( $35 \mathrm{~ms}, 32 \mathrm{~ms}$ and $41 \mathrm{~ms}$ ). The fact that the subject L2 4 did not make a pause after the second block of information and did not emphasize the word center either can be considered as acceptable since the semantically most significant piece of information (Crown Hotel) was emphasized and followed by a pause. In the given context, providing a more specific piece of information regarding the location of the hotel is possible but not inevitable.

\begin{tabular}{|l|l|l|l|l|l|l|l|l|l|l|l|l|l|l|l|}
\hline L1 1 & It & would & be & possible & In & the & Crown & Hotel & in & the & center & not & far & from & here \\
\hline L1 2 & It & would & be 32 & possible & In & the & Crown & Hotel 493 & in & the & center & not & far & from & here \\
\hline L1 3 & It & would & be & possible & In & the & Crown & Hotel 357 & in & the & center & not & far & from & here \\
\hline L1 4 & It & would & be & possible & In & the & Crown & Hotel 421 & in & the & center 253 & not & far & from & here \\
\hline L1 5 & It & would & be & possible & In & the & Crown & Hotel 405 & in & the & center & not & far & from & here \\
\hline L1 6 & It & would & be & possible & In & the & Crown & Hotel 298 & in & the & center & not & far & from & here \\
\hline
\end{tabular}

Five L1 subjects (L1 2, L1 3, L1 4, L1 5 and L1 6) produced discursive pauses after the first block of information and one subject (L1 4) produced another discursive pause after the second block of information. One L1 subject (L1 1) produced the utterance without any pause. In addition, one extremely short (32 ms) hesitation pause was observed in L1 2. Being inaudible due to its extremely short duration this pause (following a minor emphasis) may be acceptable and thus it does not hinder communication between the producer and perceiver.

Sentence 3: Das wäre das Hotel Krone, es liegt sehr zentral, nicht weit von hier.

\begin{tabular}{|l|l|l|l|l|l|l|l|l|l|l|l|l|l|}
\hline L2 1 & Das & wäre & das & Hotel & Krone 493 & es & liegt & sehr & zentral 252 & nicht & weit & von & hier \\
\hline L2 2 & Das & wäre & das & Hotel & Krone 178 & es & liegt & sehr & zentral 187 & nicht & weit & von & hier \\
\hline L2 3 & Das & wäre & das & Hotel & Krone 291 & es & liegt & sehr & zentral 127 & nicht & weit & von & hier \\
\hline L2 4 & Das & wäre & das & Hotel & Krone & es & liegt 66 & sehr & zentral 279 & nicht & weit & von & hier \\
\hline L2 5 & Das & wäre & das & Hotel & Krone 326 & es & liegt & sehr & zentral 219 & nicht & weit & von & hier \\
\hline L2 6 & Das & Wäre & das & Hotel & Krone 337 & es & liegt & sehr & zentral 298 & nicht & weit & von & hier \\
\hline L2 7 & Das & wäre & das & Hotel & Krone 405 & es & liegt & sehr & zentral 158 & nicht & weit & von & hier \\
\hline L2 8 & Das & wäre & das & Hotel & Krone 201 & es & liegt & sehr & zentral 126 & nicht & weit & von & hier \\
\hline L2 9 & Das & wäre & das & Hotel & Krone 292 & es & liegt & sehr & zentral 194 & nicht & weit & von & hier \\
\hline L2 10 & Das & wäre & das & Hotel & Krone 424 & es & liegt & sehr & zentral 116 & nicht & weit & von & hier \\
\hline
\end{tabular}

Nine L 2 subjects (L2 1, L2 2, L2 3, L2 5, L2 6, L2 7, L2 8, L2 9 and L2 10) produced discursive pauses after the first block of information after the emphasized word (Krone) and all the ten subjects made discursive pauses after the second block of information after the emphasized word (zentral). One L2 subject (L2 4) made a pause after the emphasized word liegt. Such segmentation of the 
utterance and site of the pause may not be apt in the given context and thus may be ambiguous for the perceiver. Therefore, this pause was categorized as nonfunctional.

\begin{tabular}{|l|l|l|l|l|l|l|l|l|l|l|l|l|l|}
\hline L1 1 & Das & wäre & das & Hotel & Krone 393 & es & liegt & sehr & zentral 252 & nicht & Weit & von & hier \\
\hline L1 2 & Das & wäre & das & Hotel & Krone 283 & es & liegt & sehr & zentral & nicht & Weit & von & hier \\
\hline L1 3 & Das & wäre & das & Hotel & Krone 401 & es & liegt & sehr & zentral 352 & nicht & Weit & von & hier \\
\hline L1 4 & Das & wäre & das & Hotel & Krone 299 & es & liegt & sehr & zentral 156 & nicht & Weit & von & hier \\
\hline L1 5 & Das & wäre & das & Hotel & Krone 386 & es & liegt & sehr & zentral & nicht & Weit & von & hier \\
\hline L1 6 & Das & wäre & das & Hotel & Krone 287 & es & liegt & sehr & zentral 162 & nicht & Weit & von & hier \\
\hline
\end{tabular}

All L1 subjects produced discursive pauses after the most important block of information following the emphasized expression and four subjects (L1 1, L1 3, L1 4 and L1 6) also produced discursive pauses after the second block of information, after the minor emphasis. Two L1 subjects (L1 2 and L1 5) produced the utterance only with one pause (following the major block of information), the former one $(283 \mathrm{~ms})$ can be classified as a short pause and the latter one (386 ms) as a normal/optimal pause (Sabol and Zimmermann 1984: 227-228). Such segmentation (with one pause only) may also be ascribable to the subject's individual tempo.

Sentence 4: Well, and how much is the room with a shower?

\begin{tabular}{|l|l|l|l|l|l|l|l|l|l|l|}
\hline L2 1 & Well 156 & and & how & much & is & the & room & with & a & shower? \\
\hline L2 2 & Well 273 & and & how & much & is & the & room & with & a & shower? \\
\hline L2 3 & Well 247 & and & how & much & is & the & room & with & a & shower? \\
\hline L2 4 & Well & and & how & much & is & the & room 29 & with & a & shower? \\
\hline L2 5, L2 6, L2 7, L2 8, L2 9, L2 10 & Well & and & how & much & is & the & room & with & a & shower? \\
\hline
\end{tabular}

Three L2 subjects (L2 1, L2 2 and L2 3) produced multifunctional pauses (156 $\mathrm{ms}, 273 \mathrm{~ms}, 247 \mathrm{~ms}$ ) that follow the emphasized word well indicating that the speakers were considering the options. L2 4 produced an extremely short pause following the emphasized word room $(29 \mathrm{~ms})$. The pause in question may be put into several categories (as a discursive, respiratory or hesitation pause). In the given context it was categorized as a discursive pause since the subject intended to provide an additional piece of information (with a shower). Six subjects (L2 5, L2 6, L2 7, L2 8, L2 9 and L2 10) produced their utterances without any pauses.

\begin{tabular}{|l|l|l|l|l|l|l|l|l|l|l|}
\hline L1 1, L1 2, I1 5, L1 6 & Well & and & how & much & is & the & room & with & a & shower? \\
\hline L1 3 & Well 89 & and & how & much & is & the & room & with & a & shower? \\
\hline L1 4 & Well 96 & and & how & much & is & the & room & with & a & shower? \\
\hline
\end{tabular}

Two L1 subjects (L1 3 and L1 4) produced 2 multifunctional pauses ( $89 \mathrm{~ms}$ and $96 \mathrm{~ms}$ ) after the word well and the remaining subjects uttered the question without any pause. 
Sentence 4: Ja, und wie hoch ist da der Preis mit Dusche?

\begin{tabular}{|l|l|l|l|l|l|l|l|l|l|l|}
\hline L2 1, L2 3, L2 4, 12 5, L2 6, L2 7, L2 8, 1210 & Ja & und & wie & hoch & ist & da & der & Preis & mit & Dusche? \\
\hline L2 2 & Ja 178 & und & wie & Hoch & ist & da & der & Preis & mit & Dusche? \\
\hline L2 9 & Ja 156 & und & wie & Hoch & ist & da & der & Preis & mit & Dusche? \\
\hline
\end{tabular}

Two subjects (L2 2 and L2 9) produced multifunctional pauses (178 ms and 156 $\mathrm{ms}$ ) following the word $J a$. The remaining subjects realized their utterances without any pauses.

\begin{tabular}{|l|l|l|l|l|l|l|l|l|l|l|}
\hline L1 1, L1 2, L1 3, L1, 4 & Ja & und & Wie & hoch & ist & da & der & Preis & mit & Dusche? \\
\hline L1 5 & Ja 81 & und & Wie & hoch & ist & da & der & Preis & mit & Dusche? \\
\hline L1 6 & Ja 76 & und & Wie & hoch & ist & da & der & Preis & mit & Dusche? \\
\hline
\end{tabular}

Two L1 subjects (L1 5 and L1 6) produced multifunctional pauses after the word $j a$. The other L1 subjects did not produce any pauses in this utterance.

Sentence 5: Seventy-seven Euro.

This sentence is slightly different from the German equivalent (Seventy-seven, Siebenundachtzig) in order to maintain the identical number of syllables.

\begin{tabular}{|l|l|l|}
\hline L2 1, L2 2, L2 4, L2 5, L2 7, L2 9, L2 10 & Seventy-seven & Euro \\
\hline L2 3 & Seventy-seven 140 & Euro \\
\hline L2 6 & Seventy-seven 315 & Euro \\
\hline L2 8 & Seventy-seven 286 & Euro \\
\hline
\end{tabular}

Three subjects (L2 3, L2 6 and L2 8) produced hesitation pauses (140 ms, 315 $\mathrm{ms}$ and $286 \mathrm{~ms}$ ). In all cases the pauses occur before the word EURO and are ostensibly manifestations of the subjects' uncertainty regarding the pronunciation of the word $E U R O$ (the subjects were subsequently interviewed with regard to this particular pause). The remaining subjects realized their utterances without any pauses.

\begin{tabular}{|l|l|l|}
\hline L1 1, L1 2, L13, L1 4, L1 5, L1 6 & Seventy-seven & Euro \\
\hline
\end{tabular}

All L1 subjects produced this utterance without any pause.

Sentence 5: Siebeundachtzig Euro.

\begin{tabular}{|l|l|l|}
\hline L2 1, L2 3, L2 4, L2 7, L2 8, L2 10 & Siebeundachtzig & Euro \\
\hline L2 2 & Siebeundachtzig 29 & Euro \\
\hline L2 5 & Siebeundachtzig 84 & Euro \\
\hline L2 6 & Siebeundachtzig 38 & Euro \\
\hline L2 9 & Siebeundachtzig 64 & Euro \\
\hline
\end{tabular}


Four subjects (L2 2, L2 5, L2 6 and L2 9) produced hesitation pauses (29 ms, 84 $\mathrm{ms}, 38 \mathrm{~ms}$ and $64 \mathrm{~ms}$ ) reflecting, as in the English variant, the subjects' uncertainty regarding the pronunciation of the word EURO (as revealed in the subsequent interviews with regard to this particular pause). The remaining subjects realized their utterances without any pauses.

L1 1, L1 2, L1 3, L1 4, L1 5, L1 6 Siebeundachtzig Euro

All L1 subjects produced this utterance without any pause.

Sentence 6: But that is too expensive for us!

\begin{tabular}{|l|l|l|l|l|l|l|l|}
\hline L2 1, L2 4, L2 5, L2 6, L2 7, L2 8, L2 10 & But & that & is & too & expensive & for & us! \\
\hline L2 2 & But 200 & that & is & too & expensive & for & us! \\
\hline L2 3 & But 41 & that & is & too & expensive & for & us! \\
\hline L2 9 & But 122 & that & is & too & expensive & for & us! \\
\hline
\end{tabular}

Three L2 subjects (L2 2, L2 3 and L2 9) produced expressive pauses (200 ms, $41 \mathrm{~ms}$ and $122 \mathrm{~ms}$ ) following the word but indicating that the speakers expressed their emotions: surprise, rejection and disapproval. The remaining subjects realized their utterances without any pauses.

\begin{tabular}{|l|l|l|l|l|l|l|l|}
\hline L1 1, L1 2, L13, L1 4, L1 5, L1 6 & But & that & is & too & expensive & For & us! \\
\hline
\end{tabular}

All L1 subjects produced this utterance without any pause.

Sentence 6: Das ist uns aber zu teuer!

\begin{tabular}{|l|l|l|l|l|l|l|}
\hline L2 1, L2 3, L2 5, L2 6, L2 7, L2 8, L2 9, L2 10 & Das & ist & uns & aber & zu & teuer! \\
\hline L2 2 & Das & ist & uns & aber 156 & zu & teuer! \\
\hline L2 4 & Das & ist & uns & aber 51 & zu & teuer! \\
\hline
\end{tabular}

Two L2 subjects (L2 2 and L2 4) produced two expressive pauses (156 ms and $51 \mathrm{~ms}$ ) following the word aber indicating that the speakers expressed their emotions: surprise, rejection and disapproval similarly as in the above-given English variant. The remaining subjects realized their utterances without any pauses.

\begin{tabular}{|l|l|l|l|l|l|l|}
\hline L1 1, L1 2, L13, L1 4, L1 5, L1 6 & Das & ist & uns & aber & zu & Teuer! \\
\hline
\end{tabular}

All L1 subjects produced this utterance without any pause. 
Sentence 7: Then we can try the Starlight Hostel.

\begin{tabular}{|l|l|l|l|l|l|l|l|}
\hline L2 1, L2 2, L2 6, L2 7, L2 8, L2 9, L2 10 & Then & we & can & Try & the & Starlight & Hostel \\
\hline L2 3 & Then & we & can & Try 122 & the & Starlight & Hostel \\
\hline L2 4 & Then & we & can & Try & the & Starlight & Hostel \\
\hline L2 5 & Then & we & can & Try & the & Starlight & Hostel \\
\hline
\end{tabular}

One L2 subject (L2 3) produced this utterance with a hesitation pause (122 ms). The remaining subjects realized the utterance without any pauses.

\begin{tabular}{|l|l|l|l|l|l|l|l|}
\hline L1 1, L1 2, L13, L1 4, L1 5, L1 6 & Then & we & can & try & The & Starlight & Hostel \\
\hline
\end{tabular}

All L1 subjects produced this utterance without any pause.

Sentence 7: Wir können es dann bei der Pension Stern probieren.

\begin{tabular}{|l|l|l|l|l|l|l|l|l|l|}
\hline L2 1 & Wir & können & es & dann & bei & der 81 & Pension & Stern & probieren \\
\hline $\begin{array}{l}\text { L2 2, L2 3, L2 5, L2 6, L2 7, L2 8, L2 9, } \\
\text { L2 10 }\end{array}$ & Wir & können & es & dann & bei & der & Pension & Stern & probieren \\
\hline L2 4 & Wir & können & es & dann & bei & der 105 & Pension & Stern & probieren \\
\hline
\end{tabular}

The pauses ( $81 \mathrm{~ms}$ and $105 \mathrm{~ms}$ ) observed in two L2 subjects (L2 1 and L2 4) follow the definite article der, which is emphasized. Such a shift of pause (and emphasis) may be regarded as inappropriate as it considerably changes the meaning of the utterance in the given context ("as there are more hostels of the same name, I mean specifically this one"). Therefore, the pauses in question were categorized as non-functional. The remaining subjects realized the utterance without any pauses.

\begin{tabular}{|l|l|l|l|l|l|l|l|l|l|}
\hline L1 1, L1 2, L13, L1 4, L1 5, L1 6 & Wir & können & es & dann & bei & der & Pension & Stern & probieren \\
\hline
\end{tabular}

All L1 subjects produced this utterance without any pause.

Sentence 8: Shall I call them?

\begin{tabular}{|c|c|c|c|c|c|}
\hline L2 1, L2 2, L2 3, L2 4, L2 5, L2 6, L2 7, L2 8, L2 9, L2 10 & & Shall & I & call & them? \\
\hline L1 1, L1 2, L1 3, L1 4, L1 5, L1 6 & Shall & I & call & & \\
\hline
\end{tabular}

Sentence 8: Soll ich für Sie anrufen?

\begin{tabular}{|c|c|c|c|c|c|c|}
\hline L2 1, L2 2, L2 3, L2 4, L2 5, L2 6, & L2 10 & Soll & Ich & für & Sie & anrufen? \\
\hline L1 1, & Soll & ich & für & $\mathrm{Sie}$ & & rufen? \\
\hline
\end{tabular}


Since this is a very short and simple utterance, all the L2 and L1 subjects produced it in both versions without any pause.

Sentence 9: Yes, please.

\begin{tabular}{|l|l|l|}
\hline L2 1 & Yes 245 & please \\
\hline L2 2 & Yes 50 & please \\
\hline L2 3, L2 7, L2 8, L2 9, L2 10 & Yes & please \\
\hline L2 4 & Yes 75 & please \\
\hline L2 5 & Yes 60 & please \\
\hline L2 6 & Yes 190 & please \\
\hline
\end{tabular}

Five L2 subjects (L2 1, L2 2, L2 4, L2 5 and L2 6) produced politeness pauses ( $245 \mathrm{~ms}, 50 \mathrm{~ms}, 75 \mathrm{~ms}, 60 \mathrm{~ms}$ and $190 \mathrm{~ms}$ ), which are realized in order to underline the phatic function of communication (after the word Yes). The remaining subjects realized the utterance without any pauses.

\begin{tabular}{|l|l|l|}
\hline L1 1 & Yes 47 & please \\
\hline L1 2, L2 3, L2 6 & Yes & please \\
\hline L1 4 & Yes 83 & please \\
\hline L1 5 & Yes 75 & please \\
\hline
\end{tabular}

Three L1 subjects (L1 1, L1 4 and L1 5) produced politeness pauses (47 ms, 83 $\mathrm{ms}$ and $75 \mathrm{~ms}$ ), one of extremely short and two of very short duration.

Sentence 9: $\mathrm{Ja}$, bitte.

\begin{tabular}{|l|l|l|}
\hline L2 1, L2 2, L2 4, L2 5, L2 6, L2 7, L2 8, L2 9, L2 10 & Ja & Bitte \\
\hline L2 3 & Ja 58 & Bitte \\
\hline
\end{tabular}

One subject (L2 3) produced one politeness pause (58 ms) after the word $J a$ having a similar function as in the English variant. The remaining subjects realized the utterance without any pauses.

\begin{tabular}{|l|l|l|}
\hline L1 1, L1 2, L1 3, L1 4, I1 5, L1 6 & Ja & Bitte \\
\hline
\end{tabular}

All L1 subjects produced this utterance without any pause.

The following graphs illustrate the difference between L1 and L2 subjects in the occurrence in percentage and the diversity of types of pauses. 
Graph 1. L2 (English) subjects
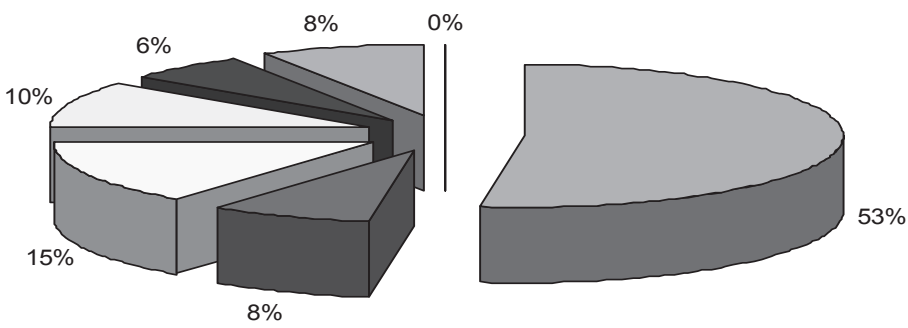

$\square$ Discursive
$\square$ Respiratory
$\square$ Hesitation
$\square$ Politeness
$\square$ Expressive
$\square$ Multifunctional
$\square$ Non-functional

Graph 1 based on the data obtained from L2 (English) subjects reveals the diversity in the occurrence of types of pauses indicating the highest frequency of discursive pause (53\%) followed by hesitation pause $(15 \%)$, politeness pause $(10 \%)$, respiratory and multifunctional pauses ( $8 \%$ each), the remaining types having a lower frequency (expressive having 6\%, nonfunctional $0 \%$ ).

Graph 2. L1 (English) subjects
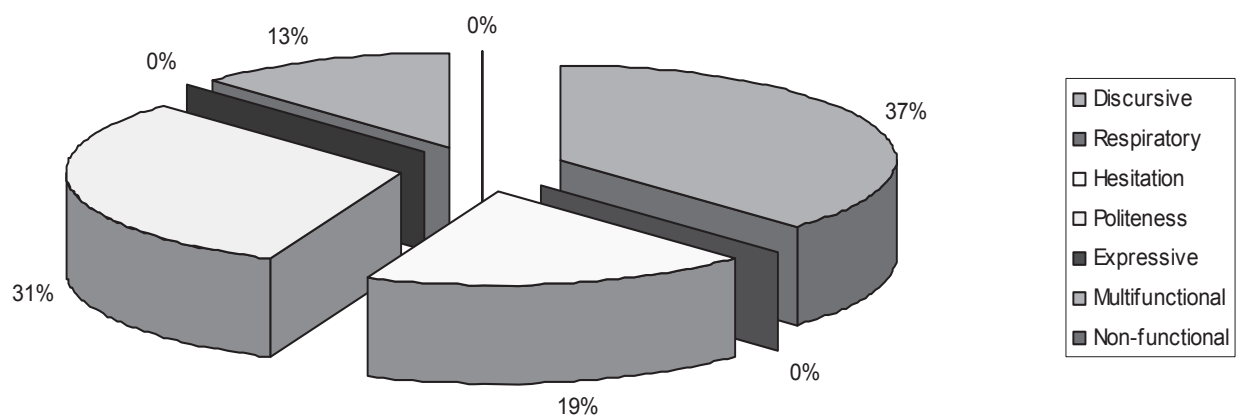

Graph 2 based on the data obtained from L1 (English) subjects indicates a lesser degree of diversity of types of pauses when compared with the L2 subjects' utterances. The highest frequency is exhibited by discursive pause (37\%), which is followed by politeness pause (31\%), hesitation pause (19\%) and, finally, multifunctional pause (13\%). The other types of pauses have no occurrence.

Graph 3. L2 (German) subjects

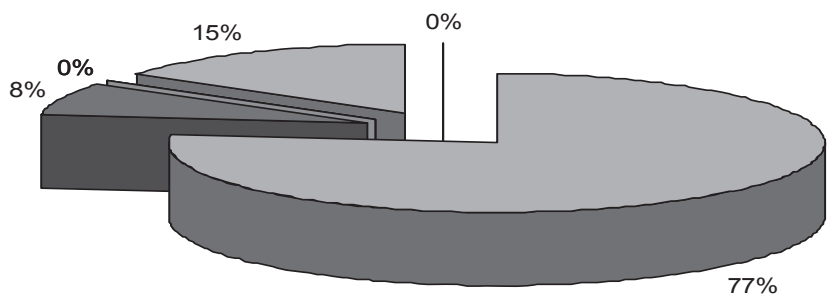


Graph 3 manifests a high diversity of pause types, a significantly higher frequency being exhibited by discursive pause (63\%) if compared with other pause types. Hesitation pause is represented by $13 \%$ and the remaining pause types exhibit very small differences in frequency (respiratory and non-functional having 7\%, expressive and multifunctional pause having $4 \%$ each and politeness pause having the lowest frequency of $2 \%$ ).

Graph 4. L1 (German) subjects

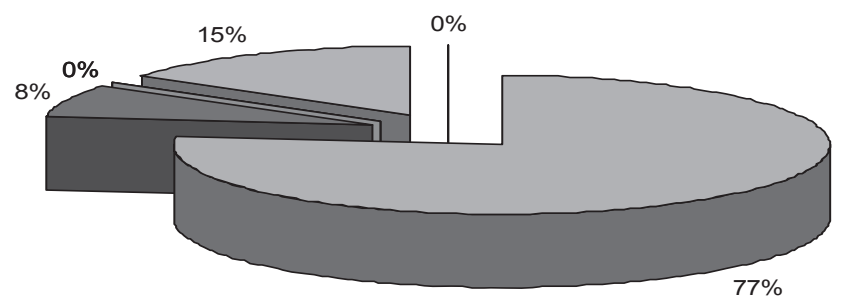

\begin{tabular}{|l|}
\hline$\square$ Discursive \\
$\square$ Respiratory \\
$\square$ Hesitation \\
$\square$ Politeness \\
$\square$ Expressive \\
$\square$ Multifunctional \\
$\square$ Non-functional
\end{tabular}

In L1 (German) subjects only three pause types are represented, namely discursive pause (with a fairly high frequency of $77 \%$ ), multifunctional (15\%) and respiratory pause (8\%). Unlike in L2 subjects' utterances, in L1 speakers' utterances other types of pauses do not occur, in other words the diversity of pause type is considerably lower.

\section{Discussion}

In accordance with prior expectations and assumptions, after comparing the L2 subjects' performances in both language versions it is possible to make preliminary conclusions that discursive pause has a dominant position and L2 subjects' utterances exhibit a higher degree of diversity of pause types than L1 subjects' utterances.

The fact that L2 speakers' oral productions (both in English and German versions) are perceived and assessed as non-fluent (staccato) revealing their deficient language competence may also be caused by inappropriate segmentation of the discourse, the distribution and frequency of pause types. As psycho-acousticians observe (cf. Zellner 1994), L2 speakers apply cognitive activities different from L1 speakers (manifested by more planning, programming and production time) and lack L1 subjects' linguistic intuition. Since an anomalous segmentation tends to perturb the listener, this feature of L2 speech impairs comprehension. L1 subjects, on the other hand, tend to plan and program their utterances in longer blocks; therefore, their segmentation of the discourse is natural and spontaneous and is not performed consciously.

Further research that will be based on a larger number of subjects, data gained from longer stretches of speech (also taking into account the subjects' individual 
tempo) may provide a more comprehensive picture of and a deeper insight into the issue.

\section{Notes}

1 The analysis presented in this paper has been conducted within two research project schemes: (i) VEGA 1/0475/08 "Comparative analysis of selected supra-segmental features (emphasis, internal sentence pause and melody) and their syntactic patterning in the English, German and Slovak languages in semantically identical micro-textual units of colloquial style;

(ii) Phonetic and Phonological Scientific Division of Linguacultural and Translational Center of Excellence in the Faculty of Arts, University of Prešov.

2 Yang (2004).

3 Dauer shows that the data from a comparative study of syllable-timed and stress-timed languages support the hypothesis of a universal property of temporal organization in languages (Dauer 1983). According to this hypothesis, speech planning is based on the existence of a 'neural clock' which controls the output of all rhythmic activities including speech production and that allows for about two "acts" per second. However, neuroscience has not found sufficient evidence for the existence of an established link between a neural pulsation of central origin and speech timing.

4 Respiratory pauses were identified by the friction noise present at higher frequencies in the broadband spectrogram.

\section{References}

Campione, Estelle and Jean Véronis (2002) 'A Large-Scale Multilingual Study of Silent Pause Duration’. In: Speech Prosody 2002, Aix-en-Provence, France. April 11-13, 2002. http:/www. isca-speech.org./archive

Dauer, R. (1983) 'Stress-timing and syllable-timing reanalyzed'. Journal of Phonetics 11, 51-62.

Sabol, Ján (2006) 'Pauza a dôraz'. In: Sabol, Ján, Iveta Bónová and Miloslava Sokolová (2006) Kultúra hovoreného prejavu. Acta Facultatis Philosophicae Universitatis Prešoviensis. Prešov: Prešovská univerzita, 171-172.

Sabol, Ján and Július Zimmermann (1979) Základy akustickej fonetiky. Košice: UPJŠ.

Sabol, Ján and Július Zimmermann (1984) 'Komunikačná hodnota pauzy'. In: Úloha reči a hudby v životním prostředí. XXIII. Akustická conference. České Budějovice: ČSVTS, 225-229.

Stock, Eberhard (1996) Deutsche Intonation. Berlin, Langenscheidt Verlag Enzyklopädie.

Strangert, Eva (2007) 'Emphasis by Pausing'. http://w2.nada.kth.se/grog/publications/ICPhS 0612.pdf

Svoboda, Aleš (2005) 'Firbasian semantic scales and comparative studies'. In: Čermák, Jan, Aleš Klégr, Markéta Malá and Pavlína Šaldová (eds.) Patterns - A Festschrift for Libuše Dušková. Praha: Filozofická fakulta Univerziy Karlovy, 217-229.

Viola, Izabel Cristina and Sandra Madureira (2008) 'The roles of pause in speech expression'. $<$ http://aune.lpl.univ-aix.fr/ sprosig/sp2008/papers/id188.pdf > .

Yang, Li-chiung (2004) 'Duration and Pauses as Cues to Discourse Boundaries in Speech Speech Prosody'. Nara, Japan. ISCA Archive. <http://www.isca-speech.org/archive>.

Zellner, Brigitte (1994) 'Pauses and the temporal structure of speech'. In: Keller, Eric (ed.) Fundamentals of speech synthesis and speech recognition, Chichester: John Wiley. 41-62. 
Magdaléna Bilá is an associate professor at the Department of English language and literature, Faculty of Humanities and Natural Sciences of the University of Prešov (Slovakia), where she teaches linguistic courses, such as Phonetics and Phonology, Introduction to Linguistics, Stylistics and Translation and Intercultural communication. She received her Ph.D. in Linguistics from the University of Prešov (Slovakia) and her post doctoral degree in linguistics from the University of Debrecen (Hungary). Her research interests include suprasegmental phonology and acquisition of L2 phonology. In her recent research and publications she has focused on L2 speakers' rhythmic patterning in English, perception of impoverished input by L2 listeners and silent pause phenomena in L2 speakers' English.

Address: Doc. PhDr. Magdaléna Bilá, Ph.D., Department of English language and literature Faculty of Humanities and Natural Sciences, The University of Prešov, 17. novembra 1, 08001 Prešov, Slovakia. [e-mail: magduska_bila@yahoo.com]

Anna Džambová is a senior lecturer at the Department of German language and translatology, Institute of German studies, Faculty of Arts of the University of Prešov (Slovakia), where she teaches linguistic courses, such as Phonetics and Phonology, Practical Phonetics, Rhetoric, Orthography and Listening comprehension skills. She received her Ph.D. in General Linguistics from the University of Prešov (Slovakia). Her research interests include German phonetics and phonology. In her recent research and publications she has focused on suprasegmental phonology, specifically intonemes in German and Slovak.

Address: PhDr. Anna Džambová, Ph.D., Institute of German Studies, Department of German language and translatology, Faculty of Arts, The University of Prešov, 17. novembra 1, 08001 Prešov, Slovakia. [e-mail: dzambova@unipo.sk] 
